\title{
NANOPARTICLE-COATED ORGANIC-INORGANIC MICROPARTICLES: EXPERIMENTAL DESIGN AND GASTROINTESTINAL TOLERANCE EVALUATION
}

\author{
Ruy Carlos R. Beck, Sandra Elisa Haas e Silvia Stanisçuaski Guterres \\ Faculdade de Farmácia, Universidade Federal do Rio Grande do Sul, Av. Ipiranga, 2752, 90610-000 Porto Alegre - RS, Brazil \\ Maria Inês Ré \\ Instituto de Pesquisas Tecnológicas do Estado de São Paulo S.A., Divisão de Química, CP 0141, \\ 01064-970 São Paulo - SP, Brazil \\ Edilson V. Benvenutti e Adriana Raffin Pohlmann* \\ Instituto de Química, Universidade Federal do Rio Grande do Sul, CP 15003, 91501-970 Porto Alegre - RS, Brazil
}

Recebido em 30/8/05; aceito em 9/12/05; publicado na web em 14/6/06

\begin{abstract}
The influences of the spray-drying parameters and the type of nanoparticles (nanocapsules or nanospheres) on the characteristics of nanoparticle-coated diclofenac-loaded microparticles were investigated by using a factorial design $3^{2}$. Gastrointestinal tolerance following oral administration in rats was evaluated. Formulations were selected considering the best yields, the best encapsulation efficiencies and the lowest water contents, presenting surfaces completely coated by nanostructures and a decrease in the surface areas in relation to the uncoated core. In vitro drug release demonstrated the influence of the nanoparticle-coating on the dissolution profiles of diclofenac. Nanocapsule-coated microparticles presented a protective effect on the gastrointestinal mucosa.
\end{abstract}

Keywords: nanocoating; nanoparticle; microparticle.

\section{INTRODUCTION}

Drug delivery systems are widely proposed to increase the efficacy and/or decrease the toxicity of drugs ${ }^{1,2}$. Since the 1980 decade different approaches were developed considering microand nanoparticles as drug carriers ${ }^{1,3-5}$. Microparticles can be prepared by several physical and chemical methods including solvent evaporation, spray-drying and in situ polymerization ${ }^{1}$. The spray-drying technique has been successfully employed in the preparation of microparticulate delivery systems $\mathrm{s}^{6-11}$. This method exhibits advantages such as a rapid and one-step process, it is applicable to heat-sensitive materials and presents an easy industrial transposition ${ }^{12}$. Previous works reported the influence of spray-drying parameters on the microparticle characteristics ${ }^{7,13,14}$. Despite the several advantages of spray-drying technique, the control of the parameters such as temperature or feeding spray rate during the process is important to avoid high moisture content or low yields of powders.

Concerning the nanoparticulated systems, in the past 15 years, polymeric nanocapsules and nanospheres were extensively studied as drug carriers (anticancers, peptides, anti-inflammatories, antibiotics) ${ }^{2,5,15-29}$. According to the literature, the model for nanospheres is a matricial polymeric structure, in which drugs would be entrapped or molecularly dispersed, while the nanocapsule is a lipophilic core surrounded by a polymeric layer, in which drugs would be dissolved in the oil or dispersed within the particle ${ }^{3,20}$. Additionally, the drug can be adsorbed at the interface particle/water ${ }^{21}$.

The main disadvantages of these aqueous colloidal systems are the physico-chemical instability due to the polymer hydrolysis, the drug leakage and/or particle agglomeration and sedimentation ${ }^{20}$. Aiming to overcome these disadvantages, our group has developed a spray-drying technique ${ }^{22,23}$ and a freeze-drying process ${ }^{24}$ to dry

*e-mail: pohlmann@iq.ufrgs.br nanocapsule and nanosphere suspensions using silicon dioxide as drying adjuvant. The nanosphere or the nanocapsule suspensions give differently, homogeneous and reproducible nanoparticle-coated microparticles after drying as observed by $\mathrm{SEM}^{25}$. In this case, drugs were encapsulated in polymeric nanoparticles ${ }^{26-28}$. The potential use of these systems as controlled delivery systems was demonstrated by the decrease of gastrointestinal toxicity of non-steroidal antiinflammatory drugs $\mathrm{s}^{28,29}$.

On the other hand, hybrid organic-inorganic microparticles were also prepared by encapsulating the drug in the inorganic core (silicon dioxide) and using unloaded-polymeric colloidal systems as coating material ${ }^{30}$. Different formulations were prepared in order to study the influence of the diclofenac in its salt or acid forms (hydrophilic and hydrophobic models), as well as the methods employed (evaporation under reduced pressure and spray-drying) on the powder characteristics. The potential application of polymeric colloidal suspensions as nanoparticle coating of microparticles was evaluated in terms of process yields, encapsulation efficiencies, and in vitro drug release. When the diclofenac (sodium salt) was employed as hydrophilic model, the powders prepared in two steps (core previously prepared) showed satisfactory gastroresistance. In a similar way, the use of diclofenac (acid form) as hydrophobic model also conducted to powders presenting good gastroresistance if the triacetin is added in nanocapsule-coated formulations.

In order to optimize the process, this work reports the use of factorial designs to evaluate the influences of the spray-drying parameters (inlet temperature and feeding spray rate) and the nanoparticle type (nanocapsule or nanosphere suspension) on the characteristics of the nanoparticle-coated diclofenac-loaded inorganic microparticles. Nanoparticle-coated microparticles were characterized by process yields, encapsulation efficiencies, water contents, and microparticle sizes. Selected formulations were also characterized by morphologic analyses, in vitro drug release and gastrointestinal tolerance following oral administration in rats. 


\section{EXPERIMENTAL PART}

\section{Materials}

Diclofenac (sodium salt) was obtained from Sigma (St. Louis, EUA); Eudragit S100 ${ }^{\circledR}$ (EUD) was supplied from Almapal (São Paulo, Brazil). Caprilic/capric triglyceride mixture was delivered from Brasquim (Porto Alegre, Brazil); sorbitan monostearate (Span $60^{\circledR}$ ) and polysorbate 80 (Tween $80^{\circledR}$ ) were supplied by Delaware (Porto Alegre, Brazil). Colloidal silicon dioxide (Aerosil 200 ${ }^{\circledR}$ ) was acquired from Degussa (São Paulo, Brazil). All others chemicals and solvents presented pharmaceutical grade and were used as received.

\section{Preparation of free acid form of diclofenac}

An aqueous solution (400 mL) of sodium diclofenac (3.0 g, $9.43 \mathrm{mmol})$ was acidified with $5 \mathrm{M} \mathrm{HCl}(5 \mathrm{~mL})$ and the precipitate (free acid form of diclofenac) was filtered and recrystallized from ethanol/water 1:1 (v/v). Colorless crystals were obtained with $90 \%$ of yield and characterized by infrared analysis (FT-IR 8300 , Shimadzu, Tokyo, Japan).

IR (v, cm-1): $3322(\mathrm{NH}), 2940$ (br, OH), $1694(\mathrm{CO}), 1587(\mathrm{C}=\mathrm{C})$ 1507 and 1453 (aromatic rings), 1160 (C-O).

\section{Preparation and characterization of colloidal suspensions}

Nanocapsules (NC) and nanospheres (NS) were prepared by the nanoprecipitation method as described by Fessi and coworkers $^{31}$. For NC preparation, the organic solution was consisted of the capric/caprilic triglyceride $(3.3 \mathrm{~mL})$, Span $60^{\circledR}(0.1532 \mathrm{~g})$, the polymer (EUD) $(1.0 \mathrm{~g})$ and acetone $(267.0 \mathrm{~mL})$. This organic phase was added under moderate magnetic stirring to an aqueous solution $(533.0 \mathrm{~mL})$ containing Tween $80^{\circledR}(0.1532 \mathrm{~g})$. The magnetic stirring was maintained for $10 \mathrm{~min}$. Thus, the acetone was eliminated and the aqueous phase concentrated by evaporation under reduced pressure to a final volume of $100 \mathrm{~mL}$ (10 $\mathrm{mg} \mathrm{mL}^{-1}$ of polymer). The NS suspensions were prepared as described for NC, omitting the capric/caprilic triglyceride.

The colloidal suspensions were characterized by $\mathrm{pH}$ measurements (Micronal, B-474, São Paulo, Brazil) and by particle size determination using photon correlation spectroscopy (PCS) after dilution of samples (500 times) with water (Milli-Q $\left.{ }^{\circledR}\right)$. The scattered light was observed at an angle of $90^{\circ}$ (Brookheaven Instruments, goniometer BI-200M/2.0 version, Holtsville, USA; BI9863 detection system; Laser He-Ne source $35 \mathrm{~mW}, 127$ model, $\lambda=632.8 \mathrm{~nm}$, Spectra Physics, Mountain View, USA).

\section{Preparation of microparticles}

To obtain the core of the microparticles (uncoated core), 50 $\mathrm{mL}$ of a diclofenac (free acid) acetone solution $\left(5.00 \mathrm{mg} \mathrm{mL}^{-1}\right.$ or $\left.17 \mathrm{mmol} \mathrm{L}^{-1}\right)$ were added of Aerosil $200^{\circledR}(1.5 \mathrm{~g})$. The acetone was removed under reduced pressure to obtain a solid product. This powder (the core) was maintained in a dessiccator at room temperature for $48 \mathrm{~h}$. At the coating step, this powder $(1.5 \mathrm{~g})$ was carefully milled in a mortar for $10 \mathrm{~min}$, and dispersed into $50 \mathrm{~mL}$ of NS or NC aqueous suspension under magnetic stirring at room temperature. The mixture was fed into a mini-spray-dryer Büchi $190^{\circledR}$ (Flawil, Switzerland) with a two-component nozzle and cocurrent flow (Air flow rate: $500 \mathrm{NL} / \mathrm{h}$; Atomizing air pressure: 2 bar). The inlet air temperature and feeding spray rate, considered as independent variables, were varied according to preliminary experiments $\left(130,150\right.$ and $170{ }^{\circ} \mathrm{C} ; 3.0,4.5$ and $6.0 \mathrm{~mL} \mathrm{~min}{ }^{-1}$, respectively). The powders were designed MP-NS or MP-NC, according to the type of the nanoparticle suspension employed (nanosphere or nanocapsule, respectively).

A physical mixture (PM) consisted of Aerosil 200 ${ }^{\circledR}$ (1.27 g) and sodium diclofenac $(0.72 \mathrm{mmol})$ was prepared as control.

\section{Experimental design}

Tables 1 and 2 show the evaluated factors and levels in the factorial design $3^{2}$. The effects of inlet temperature and feeding spray rate on production yields, water content, encapsulation efficiency and particle size were analyzed.

Table 1. Matrix of experiments of the $3^{2}$ factorial design

\begin{tabular}{lcc}
\hline Formulation & \multicolumn{2}{c}{ Factors } \\
& $\begin{array}{c}\text { Inlet air temperature } \\
\left({ }^{\circ} \mathrm{C}\right)(\mathrm{A})\end{array}$ & $\begin{array}{c}\text { Spray rate feed } \\
\left(\mathrm{mL} \mathrm{min}{ }^{-1}\right)(\mathrm{B})\end{array}$ \\
\hline $1: \mathrm{a}_{0} \mathrm{~b}_{0}$ & 0 & 0 \\
$2: \mathrm{a}_{1} \mathrm{~b}_{0}$ & 1 & 0 \\
$3: \mathrm{a}_{2} \mathrm{~b}_{0}$ & 2 & 0 \\
$4: \mathrm{a}_{0} \mathrm{~b}_{1}$ & 0 & 1 \\
$5: \mathrm{a}_{1} \mathrm{~b}_{1}$ & 1 & 1 \\
6: $\mathrm{a}_{2} \mathrm{~b}_{1}$ & 2 & 1 \\
$7: \mathrm{a}_{0} \mathrm{~b}_{2}$ & 0 & 2 \\
$8: \mathrm{a}_{1} \mathrm{~b}_{2}$ & 1 & 2 \\
$9: \mathrm{a}_{2} \mathrm{~b}_{2}$ & 2 & 2 \\
\hline
\end{tabular}

Table 2. Factors and levels available in the factorial design

\begin{tabular}{ll}
\hline Factors & Levels \\
\hline A: Inlet air temperature $\left({ }^{\circ} \mathrm{C}\right)$ & (0) 130 \\
& (1) 150 \\
B: Spray rate feed $\left(\mathrm{mL} \mathrm{min}^{-1}\right)$ & (2) 170 \\
& (0) 3.0 \\
& (1) 4.5 \\
& (2) 6.0 \\
\hline
\end{tabular}

\section{Determination of yield and encapsulation efficiency}

The yields of the formulations were calculated by the sum of the weights of all components, discounting the content of water from the suspensions. The powders (core and nanoparticle-coated microparticles) were dispersed in phosphate buffer $\mathrm{pH} 7.4$ for 60 min, at room temperature, followed by the centrifugation of the dispersions. Then, the supernatants were appropriately diluted with mobile phase and filtered through a hydrophilic membrane (GVWP, $0.22 \mu \mathrm{m}$, Millipore). The samples were analyzed by HPLC. The chromatographic system consisted of a Lichrospher ${ }^{\circledR}$ column RP 18 (250 x 4 mm, Merck, Darmstadt, Germany) and a Perkin Elmer instrument (200 Series, Shelton, EUA). The mobile phase consisted of acetonitrile/pH 5.0 phosphate buffer (60:40\% $\mathrm{v} / \mathrm{v}$ ) with a flow rate of $1.2 \mathrm{~mL} \mathrm{~min}^{-1}$. The volume injected was 20 $\mu \mathrm{L}$. Diclofenac was detected at $280 \mathrm{~nm}$. The encapsulation efficiency of each formulation was calculated by the correlation of the theoretical and the experimental diclofenac concentrations and expressed as percentages (\%). The HPLC method was validated according to the following characteristics: linearity, range, precision, accuracy and specificity ${ }^{32,33}$. This method is linear $\left(\mathrm{r}^{2}=1\right)$ in the range of 3 to $15 \mu \mathrm{g} \mathrm{mL} \mathrm{m}^{-1}$, accurate $(100.04 \pm 6.40 \%$ $-101.56 \pm 3.25 \%$ ) and precise (DPR: $1.25-1.57 \%$ and 1.47 and 
$1.91 \%$, for repeatability and intermediate precision, respectively). The specificity was tested in the presence of the microparticle adjuvants and under different $\mathrm{pH}$ media, demonstrating that these factors did not alter the diclofenac assay.

\section{Determination of water content}

The water content was determined by the Karl-Fisher coulometric method (Mettler DL 37, Greifensee, Switzerland). Experiments were carried out in triplicate.

\section{Morphological characterization}

\section{Scanning electron microscopy}

The uncoated core and the nanoparticle-coated microparticles were examined under scanning electron microscopy (SEM) (Jeol Scanning Microscope, JSM-5800, Tokyo, Japan) at different magnifications between 1,000x and 90,000x. Samples were analyzed after they had been gold sputtered (Jeol Jee 4B SVG-IN, Tokyo, Japan). These analyses were carried out in the Centro de Microscopia (UFRGS, Porto Alegre, Brazil).

\section{Surface area and pore size distribution}

The nitrogen adsorption-desorption isotherms of previous degassed organic-inorganic solids under vacuum at $40{ }^{\circ} \mathrm{C}$ were determined at liquid nitrogen boiling point in a home-made volumetric apparatus, using nitrogen as probe. The specific surface areas of powders were determined by the BET multipoint technique $^{34}$ and the pore size distribution was obtained using BJH method ${ }^{35}$.

\section{In vitro drug release}

The in vitro drug release experiments were carried out using a flow-through cell technique. The apparatus consisted by recycling flow-through cells (Desaga, Wiesloch, Germany) connected to a peristaltic pump (Desaga, Wiesloch, Germany). The flow rate was $1 \mathrm{~mL} \mathrm{~min}{ }^{-1}$. Release experiments were carried out at $37 \pm 0.5{ }^{\circ} \mathrm{C}$, using dissolution media at $\mathrm{pH} 5.0$ or $\mathrm{pH} 7.4$ (phosphate buffer). An exact amount of each powder (equivalent to $6.80 \times 10^{-3} \mathrm{mmoL}$ of diclofenac) was placed in each cell. Samples were collected at predetermined time intervals, diluted (if necessary), and filtered through a hydrophilic membrane (GVWP, $0.22 \mathrm{~mm}$, Millipore) for HPLC analyses. Experiments were carried out in triplicate.

The dissolution profiles of diclofenac from microparticles were analyzed by a) ANOVA-based method (point to point comparison), and b) Model-dependent methods (mathematical models are showed in Table 3, MicroMath Scientist ${ }^{\circledR}$ software, Salt Lake City, USA).

Table 3. Categories of employed methods to compare the dissolution profiles

\begin{tabular}{lll}
\hline Approach & Method & Equation $^{\mathrm{a}, \mathrm{b}, \mathrm{c}}$ \\
\hline ANOVA-based & Multiple univariate & - \\
method & ANOVA & $\%$ diss $=\mathrm{kt}$ \\
Model-dependent & Zero-order & $\%$ diss $=100\left(1-\mathrm{e}^{-\mathrm{kt}}\right)$ \\
& First-order & $\%$ diss $=$ \\
& Biexponential & $100\left[1-\left(\mathrm{A} \cdot \mathrm{e}^{-\mathrm{k} \cdot \mathrm{t}}+\mathrm{B}^{\left.-\mathrm{e}^{-\mathrm{k} \cdot \mathrm{t}}\right)}\right.\right.$ \\
& Weibull & $\%$ diss $=100\left[1-\mathrm{e}^{-(\mathrm{t} / \mathrm{d}) \mathrm{b}}\right]$ \\
\hline
\end{tabular}

a $\%$ diss: percentage dissolved at time $\mathrm{t} ;{ }^{\mathrm{b}} \mathrm{k}$ and $\mathrm{k}$ ': dissolution rate constants; ${ }^{c} \mathrm{~T}_{\mathrm{d}}$ : time at which $63.2 \%$ of the material is dissolved; $\beta$ : shape parameter.

\section{Gastrointestinal tolerance}

Experiments were carried out on male Wistar rats, weighing between 250 and 350 g (Biotério Central, UFRGS, Porto Alegre, Brazil). The protocol was approved by the Ethical Committee (deliberation 2004/293, UFRGS, Porto Alegre, Brazil). The animals were divided into groups of ten. The groups were kept in separate cages and the rats were allowed to eat and drink ad libitum. The diclofenac-loaded formulations and sodium diclofenac aqueous solution were given at a dose of $20 \mathrm{mg} \mathrm{kg}^{-1}$ of diclofenac by the intragastric route. The formulations were administered daily for 3 consecutive days. Twenty-four hours after the third administration the rats were decapitated following laparatomy. In order to quantify gastrointestinal lesions the stomach was opened along the greater curvature and the intestine (duodenum, jejunum and ileum) was slit open opposite the attached mesenteric tissue. The organs were washed with normal saline $(0.9 \% \mathrm{NaCl})$ to remove luminal contents and the mucosal surfaces were examined. Lesions were scored for each organ according to an arbitrary scale as previously reported ${ }^{36}$. The mean organ lesional index was calculated for each organ in all animals of the same group and then dividing the total lesional score sum by the number of animals in each group.

\section{Statistical analysis}

The factorial design statistical analysis was carried out through a two-way analysis of variance. One-way analysis of variance was employed in the comparison of the experimental data obtained from the drug release studies. Post-hoc multiple comparisons were done by Tukey's test or $t$ test (particle size) for significance at $p$-values less than 0.05. Statistical comparisons of the gastrointestinal lesional indexes in rats were conducted using the Kruskal-Wallis analysis of variance by rank.

\section{RESULTS AND DISCUSSION}

\section{Polymeric colloidal suspensions}

Eudragit $\mathrm{S} 100^{\circledR}$ was chosen as polymer because its gastric resistance enables it to be employed in modified release systems ${ }^{37}$. Nanosphere and nanocapsules aqueous suspensions prepared with Eudragit S100 ${ }^{\circledR}$ were used as an organic nanostructured coating for drug-loaded inorganic microparticles. These polymeric suspensions were prepared by nanoprecipitation of polymer using capric/caprilic triglyceride mixture, as oil, in the case of nanocapsules (NC), and omitting it in the case of nanospheres (NS). The polymeric colloidal suspensions, $\mathrm{NC}$ and $\mathrm{NS}$, presented acid $\mathrm{pH}$ values $(3.61 \pm 0.05$ and $3.60 \pm 0.01$, respectively) and particle sizes of $119 \pm 1$ and 67 $\pm 9 \mathrm{~nm}$, respectively.

\section{Experimental design: effects of spray-drying factors on nanoparticle-coated microparticles characteristics}

The core composed of diclofenac (acid) and silicon dioxide was obtained with $100 \%$ of yield by an evaporation process, presenting an encapsulation efficiency of $91.03 \pm 3.57 \%$. The morphological analyses of the powder of the core showed irregular shaped microparticles, presenting a surface similar to the raw silicon dioxide ${ }^{30}$.

\section{NS-coated microparticles}

The NS-coated microparticles (MP-NS) presented yields between 48 and $60 \%$ (Table 4$)$. The inlet temperature did not affect this parameter $(\mathrm{p}>0.05)$. On the other hand, these yields were 
Table 4. Yields, encapsulation efficiencies, particle sizes and water content for the NS-nanocoated microparticles (MP-NS)

\begin{tabular}{lcccc}
\hline Formulation & $\begin{array}{c}\text { Yield } \\
(\% \pm \mathrm{SD})\end{array}$ & $\begin{array}{c}\text { Encapsulation efficiency } \\
(\% \pm \mathrm{SD})\end{array}$ & $\begin{array}{c}\text { Particle size } \\
(\mu \mathrm{m}) \mathrm{d}_{4.3}\left(\mathrm{~d}_{0.1}-\mathrm{d}_{0.9}\right)\end{array}$ & $\begin{array}{c}\text { Water content } \\
(\% \pm \mathrm{SD})\end{array}$ \\
\hline MP-NS-1 & $53 \pm 3^{\mathrm{a}, \mathrm{b}, \mathrm{c}}$ & $89.01 \pm 3.21^{\mathrm{a}}$ & $12.21(1.56-33.67)$ & $1.87 \pm 0.08$ \\
MP-NS-2 & $52 \pm 4^{\mathrm{a}, \mathrm{b}, \mathrm{c}}$ & $101.50 \pm 7.02^{\mathrm{c}}$ & $16.44(1.49-46.77)$ & $2.09 \pm 0.10$ \\
MP-NS-3 & $58 \pm 5^{\mathrm{b}, \mathrm{c}}$ & $91.21 \pm 2.08^{\mathrm{a}, \mathrm{b}}$ & $18.20(1.58-52.25)$ & $2.04 \pm 0.11$ \\
MP-NS-4 & $57 \pm 5^{\mathrm{b}, \mathrm{c}}$ & $99.37 \pm 5.42^{\mathrm{c}}$ & $15.87(1.49-45.46)$ & $2.02 \pm 0.01$ \\
MP-NS-5 & $60 \pm 2^{\mathrm{c}}$ & $98.64 \pm 2.31^{\mathrm{b}, \mathrm{c}}$ & $14.73(1.54-41.97)$ & $1.85 \pm 0.13$ \\
MP-NS-6 & $55 \pm 3^{\mathrm{b}, \mathrm{c}}$ & $88.93 \pm 3.17^{\mathrm{a}}$ & $15.41(1.40-43.14)$ & $2.18 \pm 0.19$ \\
MP-NS-7 & $48 \pm 4^{\mathrm{a}}$ & $102.16 \pm 2.41^{\mathrm{c}}$ & $12.83(1.40-36.88)$ & $2.16 \pm 0.01$ \\
MP-NS-8 & $49 \pm 6^{\mathrm{a}, \mathrm{b}}$ & $104.29 \pm 2.53^{\mathrm{c}}$ & $15.44(1.38-45.63)$ & $2.12 \pm 0.14$ \\
MP-NS-9 & $50 \pm 4^{\mathrm{a}, \mathrm{b}}$ & $99.72 \pm 3.44^{\mathrm{c}}$ & $21.98(1.61-60.74)$ & $2.15 \pm 0.09$ \\
\hline
\end{tabular}

Means, in column, with the same letter are not significantly different (ANOVA, Tukey test).

significantly $(\mathrm{p}<0.05)$ influenced by the feeding spray rate. The highest feeding spray rate $\left(6 \mathrm{~mL} \mathrm{~min}^{-1}\right)$ led to the lowest yields (MP-NS-7, MP-NS-8 and MP-NS-9). Similar results were obtained by Billon and co-workers ${ }^{14}$ in the evaluation of the effects of the spray-drying parameters on the preparation of microparticles of sodium carboxymethylcellulose, used as polymer, which process yields were considerably increased by reducing feeding spray rate.

Concerning the encapsulation efficiencies, the values were in the range between $88.93 \pm 3.17$ and $104.29 \pm 2.53 \%$ (Table 4). These results are influenced by both parameters (feeding spray rate and inlet temperature) and by their interactions. The highest feeding spray rate $\left(6 \mathrm{~mL} \mathrm{~min}^{-1}\right)$ gave the highest encapsulation efficiencies (MP-NS-7, MP-NS-8, MP-NS-9). At $4.5 \mathrm{~mL} \mathrm{~min}^{-1}$ and $6.0 \mathrm{~mL} \mathrm{~min}{ }^{-1}$, the increasing of the inlet temperature caused a decrease in the encapsulation efficiency.

The particle sizes $\left(d_{4.3}\right)$ ranged from 12 to $22 \mu \mathrm{m}$ (Table 4$)$. At 3 and $6 \mathrm{~mL} \mathrm{~min}^{-1}$, the particle sizes raised with the increase in the inlet temperature from 12.21 to $18.20 \mu \mathrm{m}$ and from 12.83 to 21.98 $\mu \mathrm{m}$, respectively. Furthermore, all powders presented water content below $2.30 \%(1.76-2.28 \%)$, showing that the level values applied of temperature and feeding spray rate were able to dry the formulations.

\section{NC-coated microparticles}

The NC-coated microparticles (MP-NC) presented yields between 34 and $63 \%$ (Table 5). In a general rule, the yields for MPNC series were lower than those for MP-NS series (Table 4). These results can be explained by the stronger adhesion of MP-NC powders than MP-NS powders in the drying chamber. The exception was the formulation MP-NC-3, which presented $63 \%$ of yield (Table 5). The yields were significantly influenced $(\mathrm{p}<0.05)$ by the inlet temperature and the feeding spray rate. At $130{ }^{\circ} \mathrm{C}, 150{ }^{\circ} \mathrm{C}$ and $170{ }^{\circ} \mathrm{C}$, the highest yields were obtained using the lowest feeding spray rate (3 mL min ${ }^{-1}$ ) (MP-NC-1 MP-NC-2, MP-NC-3, respectively).

The encapsulation efficiencies ranged between $105.15 \pm 3.44$ and $160.55 \pm 6.80 \%$ (Table 5). Only the formulation MP-NC-3 presented an acceptable drug recovery $(105.15 \pm 3.44 \%)$. All other recoveries showed an anomalous high drug concentration in the powders after the drying process (Table 5). These values $(114.82 \pm 3.86$ to $160.55 \pm 6.80 \%)$ could be explained by the segregation of powders due to the adhesion of part of the samples on the drying chamber. Indeed, the highest recoveries were correlated with the lowest yields (MP-NC-4, MP-NC-5, MP$\mathrm{NC}-7$, and MP-NC-8)

The inlet temperature has significantly influenced the particle sizes, which varied from 12.89 to $61.67 \mu \mathrm{m}$ (Table 5). As a general form, the increase in the inlet temperature decreased the microparticle sizes (MP-NC-3, MP-NC-6, and MP-NC-9). Besides, all powders presented water content below $1.50 \%(1.05-1.48 \%)$.

\section{Scanning electron microscopy (SEM)}

SEM analyses were conducted in order to verify the effectiveness of nanoparticle-coating. The formulations (MP-NS series and MP-NC series) were compared with the core and with the physical mixture of raw materials (PM).

The uncoated core and the PM presented rugged surfaces with the presence of some cavities (Figure 1). In comparison, the MPNS surfaces of all formulations presented nanostructures with 60$70 \mathrm{~nm}$ of diameter, while for the MP-NC series only the MP-NC-3 (Figure 1) surfaces showed homogeneous coating by the presence of nanostructures about 170-200 nm. In general, the NC-coated microparticles presented irregularly coated particles as depicted in the Figure 2 for MP-NC-1. These results corroborate with the

Table 5. Yields, encapsulation efficiencies, particle sizes and water content for the NC-nanocoated microparticles (MP-NC)

\begin{tabular}{lcccc}
\hline Formulation & $\begin{array}{c}\text { Yield } \\
(\% \pm \mathrm{SD})\end{array}$ & $\begin{array}{c}\text { Encapsulation efficiency } \\
(\% \pm \mathrm{SD})\end{array}$ & $\begin{array}{c}\text { Particle size } \\
(\mu \mathrm{m}) \mathrm{d}_{4.3}\left(\mathrm{~d}_{0.1}-\mathrm{d}_{0.9}\right)\end{array}$ & $\begin{array}{c}\text { Water content } \\
(\% \pm \mathrm{SD})\end{array}$ \\
\hline MP-NC-1 & $54 \pm 11^{\mathrm{b}}$ & $119.69 \pm 16.43^{\mathrm{a} . b}$ & $23.44(1.49-60.47)^{\mathrm{b}}$ & $1.48 \pm 0.20$ \\
MP-NC-2 & $44 \pm 8^{\mathrm{a}}$ & $142.05 \pm 30.27^{\mathrm{b} . \mathrm{c}}$ & $49.35(5.20-113.20)^{\mathrm{b}}$ & $1.05 \pm 0.03$ \\
MP-NC-3 & $63 \pm 7^{\mathrm{b}}$ & $105.15 \pm 3.44^{\mathrm{a}}$ & $12.89(1.18-34.63)^{\mathrm{a}}$ & $1.11 \pm 0.03$ \\
MP-NC-4 & $34 \pm 6^{\mathrm{a}}$ & $160.55 \pm 6.80^{\mathrm{c}}$ & $53.56(8.85-115.40)^{\mathrm{b}}$ & $1.10 \pm 0.02$ \\
MP-NC-5 & $34 \pm 6^{\mathrm{a}}$ & $142.98 \pm 21.05^{\mathrm{b} . c}$ & $53.88(5.36-120.10)^{\mathrm{b}}$ & $1.08 \pm 0.02$ \\
MP-NC-6 & $47 \pm 5^{\mathrm{a}}$ & $114.82 \pm 3.86^{\mathrm{a} \cdot \mathrm{b}}$ & $17.30(1.24-46.08)^{\mathrm{a}}$ & $1.11 \pm 0.10$ \\
MP-NC-7 & $34 \pm 8^{\mathrm{a}}$ & $136.23 \pm 11.29^{\mathrm{b} . c}$ & $61.67(9.20-129.80)^{\mathrm{b}}$ & $1.15 \pm 0.08$ \\
MP-NC-8 & $34 \pm 2^{\mathrm{a}}$ & $150.58 \pm 2.34^{\mathrm{c}}$ & $50.66(6.08-112.30)^{\mathrm{b}}$ & $1.06 \pm 0.05$ \\
MP-NC-9 & $37 \pm 8^{\mathrm{a}}$ & $126.27 \pm 4.78^{\mathrm{a} . \mathrm{b}}$ & $27.62(1.77-69.44)^{\mathrm{b}}$ & $1.06 \pm 4.96$ \\
\hline
\end{tabular}

Means, in column, with the same letter are not significantly different (ANOVA, Tukey test). 


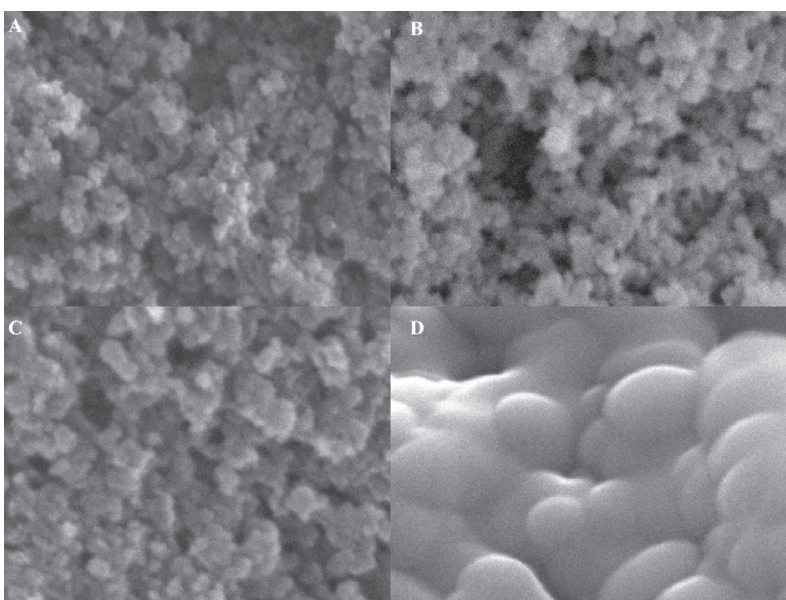

Figure 1. SEM micrographs (width: $1.39 \mu \mathrm{m}$ ) of (A) uncoated core, (B) physical mixture of raw materials, $(C)$ nanosphere-coated microparticle (MPNS-5) and (D) nanocapsule-coated microparticle (MP-NC-3)

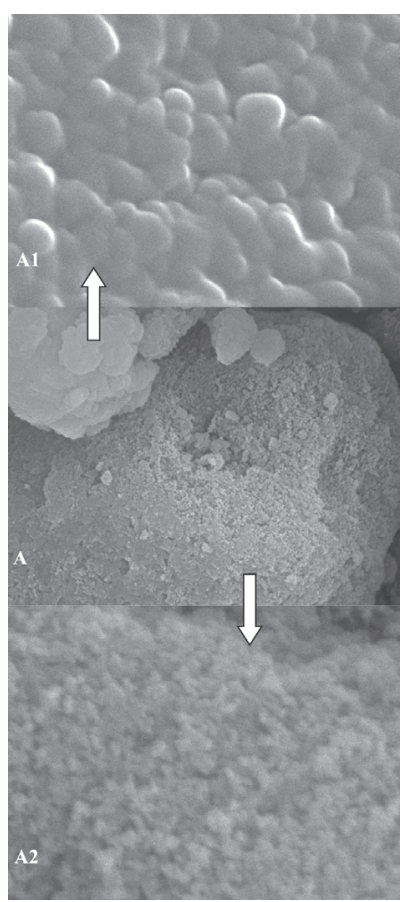

Figure 2. SEM micrographs of NC-coated microparticles at different magnifications: (A) particles from the sample of MP-NC-1 (width $=18.90$ $\mu \mathrm{m}) ;(\mathrm{Al})$ and (A2) particles in detail from $A$ (width $=2.93 \mu \mathrm{m})$

previous hypothesis of the segregation of powders during the spraydrying process, which was raised to explain the anomalous high drug recoveries (> 110\%) measured for formulations in the MPNC series, excepting for MP-NC-3.

\section{Selection of formulations}

The best formulation in each series was selected from the factorial design analysis for the subsequence experiments. In this case, the MPNS-5 and MP-NC-3 were chosen considering the best yields (presenting the lowest standard errors), the best encapsulation efficiencies (around $100 \%$ ), and the lowest water contents (below 2\%). Furthermore, the MP-NS-5 and the MP-NC-3 formulations showed the microparticle surfaces completely and homogeneously coated by the nanostructures
(SEM). For MP-NS series, it was also considered the lowest practicable inlet temperature correlated with the highest feeding spray rate.

\section{Surface area and pore size distribution}

The surface area and pore size distribution were determined for MP-NS-5 and MP-NC-3, as well as for the uncoated core and commercial colloidal silicon dioxide. The uncoated core presented a reduction in its surface area $\left(163 \mathrm{~m}^{2} \mathrm{~g}^{-1}\right)$ in relation to the commercial colloidal silicon dioxide $\left(214 \mathrm{~m}^{2} \mathrm{~g}^{-1}\right)$. The pores of Aerosil $200^{\circledR}$ are formed by the agglomeration of its primary particles $^{38}$. In this way, the presence of the drug in these pores can explain the decrease in the surface area of the uncoated core. After coating the core using the polymeric colloidal suspensions (nanospheres or nanocapsules), it was observed an additional decreases in the surface areas and pore volumes for the formulations MP-NS-5 $\left(131 \mathrm{~m}^{2} \mathrm{~g}^{-1}, 0.15 \mathrm{~cm}^{3} \mathrm{~g}^{-1}\right)$ and MP-NC-3 $\left(61 \mathrm{~m}^{2} \mathrm{~g}^{-1}, 0.04\right.$ $\left.\mathrm{cm}^{3} \mathrm{~g}^{-1}\right)$. These reductions in the surface areas and pore volumes could be explained by a supplementary reduction in the nitrogen accessibility to the pores in comparison to the uncoated core.

The pore size distributions of commercial silicon dioxide (Aerosil $200^{\circledR}$ ), uncoated core and the nanoparticle-coated microparticles (MPNS-5 and MP-NC-3) are showed in the Figure 3. For the MP-NC-3 powder, it could be observed a decrease in the mesoporous region (pore between $2 \mathrm{~nm}$ and $50 \mathrm{~nm}$ ), while for the MP-NS-5 no significant variation was detected. These results could be related to the more lipophilic nature of nanocapsules than the nature of nanospheres, due to the presence of an oil core in the former.

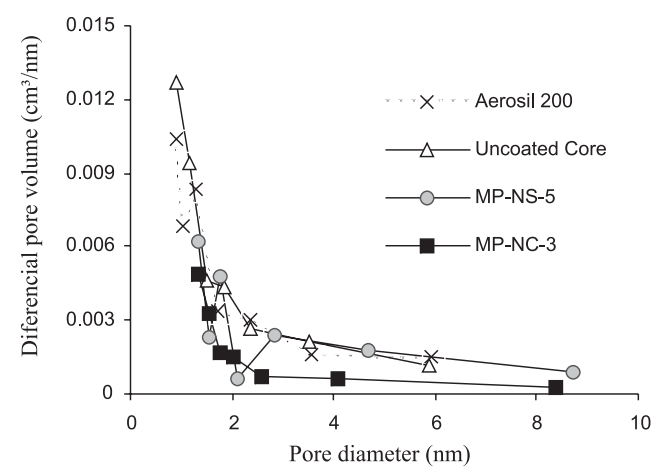

Figure 3. Pore size distribution of Aerosil $200^{\circledR}$, uncoated-core, NS-coated microparticles (MP-NS-5) and NC-coated microparticles (MP-NC-3) obtained by BJH method

\section{In vitro drug release}

The diclofenac $\left(\mathrm{p}_{\mathrm{a}} 3.8 \text { at } 25{ }^{\circ} \mathrm{C}\right)^{39}$ is soluble in aqueous solutions presenting $\mathrm{pH}$ values higher than 6 , due to the ionization of its acid function. In this way, its solubility improves with the increase of $\mathrm{pH}$ values.

The drug release profiles were determined in vitro using phosphate buffer at pH 5.0 and 7.4 (Figures 4 and 5, respectively). At $\mathrm{pH}$ 5.0, the uncoated core presented a diclofenac release of $17 \%$ after $60 \mathrm{~min}$, and $53 \%$ after $360 \mathrm{~min}$, while from the physical mixture (PM), the drug released was $51 \%$ after $60 \mathrm{~min}$, and $101 \%$ after $360 \mathrm{~min}$. The nanoparticle-coated microparticles (MP-NS-5 and MP-NC-3) presented similar values ( $\mathrm{p}>0.05)$ after $60 \mathrm{~min}(20$ and 18\%). However, after 360 min MP-NS-5 presented a drug release of $56 \%$ and MP-NC-3 showed a value of $71 \%$. This difference $(\mathrm{p} \leq 0.05)$ is in agreement with our previous results, from which we can suggest that the drug is more superficially 
associated (around 80\%) with the particles in the case of NC-coated microparticles than in the case of uncoated core ${ }^{30}$.

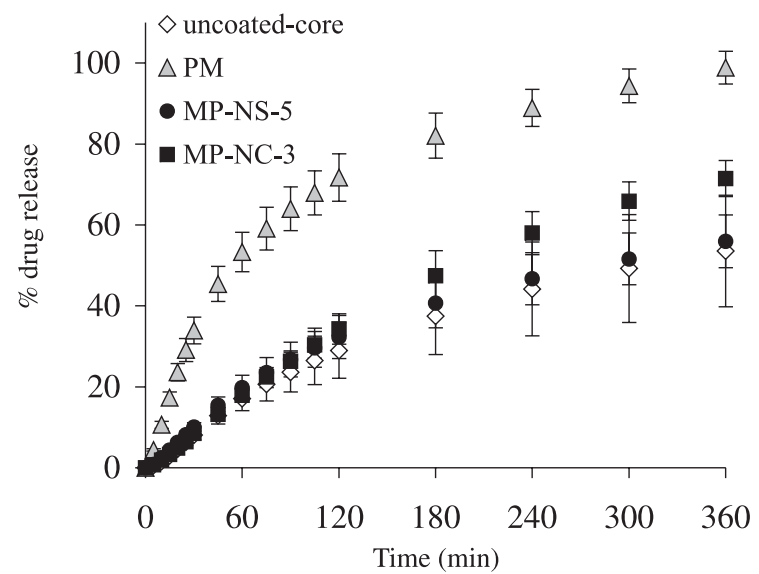

Figure 4. Diclofenac release profiles at phosphate buffer $\mathrm{pH} 5.0$ from the uncoated core, physical mixture (PM), NS-coated microparticles (MP-NS5), and NC-coated microparticles (MP-NC-3)

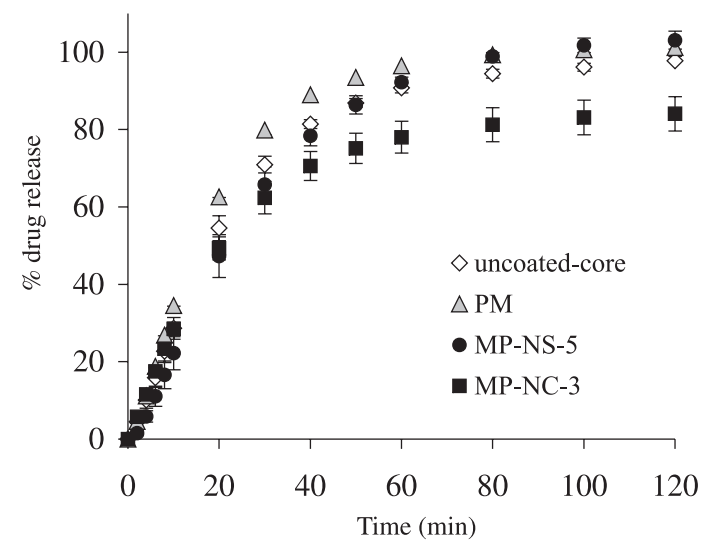

Figure 5. Diclofenac release profiles at phosphate buffer $p H 7.4$ from the uncoated core, physical mixture (PM), NS-coated microparticles (MP-NS$5)$, and $N C$-coated microparticles (MP-NC-3)

The mathematical models (Table 3) of release profiles were applied and the selection of the best model considered the correlation coefficient (r), the model selection criteria (MSC) and the graphic adjustment.

At $\mathrm{pH}$ 5.0, the best fitting was the biexponential equation for the uncoated core $(r=0.9995$, MSC $=6.4559), \mathrm{PM}(\mathrm{r}=0.9992$, MSC $=5.9779)$ and MP-NS-5 $(r=0.9997$, MSC $=6.9108)$. In these cases, the burst release observed rate constants were $k=0.0078, k$ $=0.0337$, and $k=0.0104 \mathrm{~min}^{-1}$, respectively. Otherwise, the slow release rate constants for the same formulations (uncoated core, PM and MP-NS-5) were $k^{\prime}=0.0001, k^{\prime}=0.0080$, and $k^{\prime}=0.0012$ $\min ^{-1}$, respectively. Comparing the $k$ values determined for the uncoated core and for the MP-NS-5, which are 3 to 4 times lower than that calculated for the PM, we can suggest that an amount of drug is internalized in the microparticles of both the uncoated core and MP-NS-5. This hypothesis is reinforced by the observation of $A$ parameters from the profiles of the uncoated core $(39 \%)$ and of the MP-NS-5 (35\%), which correspond to the free and/or adsorbed drug percentages in the formulations. The percentage of small crystals in the PM formulation corresponds to $32 \%$ in the mixture.
Regarding the observed rate constants of the sustained phase, the drug was released from MP-NS-5 slower than from PM, but in a similar way to the uncoated core. However, the MP-NS-5 presented lower standard deviation values than the uncoated core.

On the other hand, the best fitting was the monoexponential equation for the MP-NC-3 $(r=0.9997$; MSC $=5.8505)$. The release rate constant for this formulation was $0.0035 \mathrm{~min}^{-1}$. Considering the graphical adjustment, it was observed a lag time for the drug release. Thus, the Weibull model was applied to these data, furnishing a correlation coefficient of 0.9998 and a MSC of 7.2593. The calculated lag time was $\mathrm{t}_{0}=3.25 \mathrm{~min}$ and the time at which $62.3 \%$ of drug was dissolved $\left(\mathrm{T}_{\mathrm{d}}\right)$ was $267.60 \mathrm{~min}$, describing a Sshaped release profile $(\beta=1.0405)$.

At $\mathrm{pH} 7.4$, the polymer is dissolved ${ }^{37}$, promoting the prompt release of the drug from coated formulations by dissolution of the drug and/or erosion of the polymer. The drug release reached $100 \%$ after $65 \mathrm{~min}$ for PM, after $80 \mathrm{~min}$ for MP-NS-5, and $120 \mathrm{~min}$ for uncoated core. On the other hand, the MP-NC-3 formulation reached $84 \%$ of drug release after $120 \mathrm{~min}$. After this time, the quantification limit (HPLC) of drug was achieved.

At $\mathrm{pH} 7.4$, the best fitting was the monoexponential equation for all the formulations (uncoated core: $r=0.9984$, MSC $=5.1493$; PM: $r=0.9983$, MSC $=4.5028 ;$ MP-NS-5: $r=0.9979$, MSC $=$ 3.9371; and MP-NC-3: $\mathrm{r}=0.9904, \mathrm{MSC}=3.1248$ ). The release constants were $k=0.0380, k=0.0497, k=0.0343$, and $k=0.0283$ $\min ^{-1}$, respectively. Comparing the observed rate constants it can be observed that the diclofenac is slower released from the uncoated core (1.31 times), MP-NS-5 (1.45 times) and MP-NC-3 (1.75 times) than from the PM. These results showed that NC-containing formulation presents a more lipophilic nature than the other formulations. This chemical nature affected the diclofenac release from MP-NC-3.

\section{Gastrointestinal tolerance}

Diclofenac was chosen as model of drug because its hydrophobic characteristics, as well as gastrointestinal side-effects, such as irritation, ulceration and mucosal damage ${ }^{40}$. These characteristics allow designing an in vivo experiment to evaluate the effectiveness of the polymeric nanoparticle-coating used to prepare the microparticles MP-NS-5 and MP-NC-3 (Figure 6).

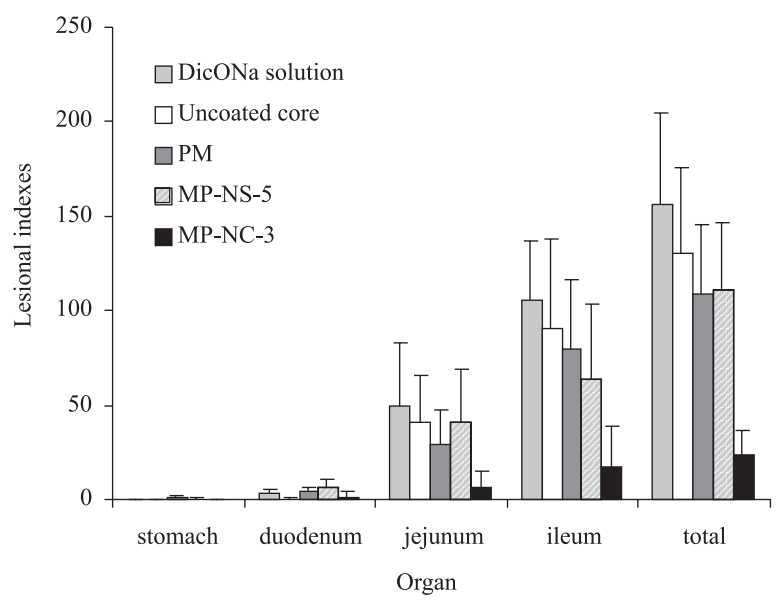

Figure 6. Mean organ lesional indexes following three consecutive daily doses of $20 \mathrm{mg} \mathrm{kg}^{-1}$ of diclofenac sodium solution (DicONa solution), uncoated core, physical mixture (PM), NS-coated microparticles (MP-NS-5), and NCcoated microparticles (MP-NC-3) 
All the formulations (sodium diclofenac solution, uncoated core, PM, MP-NS-5 and MP-NC-3) presented low lesional indexes for the stomach (less than 1), which did not differ significantly among the groups $(\mathrm{p}<0.05)$. These results correlate well with those reported for non-steroidal anti-inflammatory drugs using the same animal mode ${ }^{28,29,36,41}$. Concerning the duodenum, few pointed ulcerations were observed and the lesional indexes were: $3.61 \pm 2.09$ for diclofenac sodium solution, $0.50 \pm 0.71$ for uncoated core, $4.00 \pm 2.98$ for PM, $6.00 \pm 4.99$ for MP-NS-5 and $1.00 \pm 3.33$ for MP-NC-3. The uncoated core and the MP-NC-3 presented significant protective effect in duodenum when compared with the other formulations $(\mathrm{p}<0.05)$.

Lesional indexes in the jejunum were: $49.67 \pm 33.48$ for diclofenac sodium solution, $41.10 \pm 25.06$ for uncoated core, 29.50 \pm 18.04 for PM, $40.50 \pm 28.97$ for MP-NS-5, and $6.20 \pm 9.28$ for MP-NC-3. An important protective effect $(\mathrm{p}<0.05)$ against mucosal toxicity of diclofenac was observed for MP-NC-3. This result correlates well with that reported in our previous work for spraydried diclofenac-loaded nanocapsules ${ }^{29}$, in which silicon dioxide was used as drying adjuvant and the drug was nanoencapsulated. On the other hand, the uncoated core presented a different behavior in the jejunum when compared with the previous reported formulations ${ }^{29}$, in which silicon dioxide and diclofenac (acid or salt, with or without polysorbate 80 ) were used. The lack of the protective effect observed for the uncoated core could be related to the higher ratio of drug/ silicon dioxide employed in the present work $(0.5: 3.0 \mathrm{w} / \mathrm{w})$ than the ratio used in the previous work $(0.1: 3: 00 \mathrm{w} / \mathrm{w})$.

The highest lesional indexes were observed in the ileum: 106.11 \pm 30.69 for diclofenac sodium solution, $90.80 \pm 47.49$ for uncoated core, $79.90 \pm 36.32$ for PM, $64.10 \pm 38.99$ for MP-NS-5, $17.00 \pm$ 21.41 for MP-NC-3. As well as observed for jejunum, only the MP-NC-3 formulation presented a significant $(\mathrm{p}<0.05)$ protective effect of the gut wall.

The total lesional indexes calculated by the sum of the partial lesional indexes were: $156.11 \pm 48.54$ for diclofenac sodium solution, $132.40 \pm 45.71$ for uncoated core, $109.10 \pm 35.85$ for PM, $110.80 \pm 35.31$ for MP-NS-5, and $24.20 \pm 12.68$ for MP-NC-3. These values showed the significant effectiveness of MP-NC-3 to protect the gut wall from ulceration.

In conclusion, the control of processing variables (inlet temperature and feeding spray rate) allowed obtaining nanosphere or nanocapsule-coated microparticles with satisfactory yields, particle sizes, encapsulation efficiencies and low water contents. The overall results from physico-chemical characterization demonstrated the morphological effectiveness of nanoparticle-coating process.

The in vitro drug release experiments showed the influence of the nanosphere or nanocapsule-coating on the dissolution profiles of diclofenac from microparticles. Following oral administration in rats, for the diclofenac-loaded nanosphere-coated microparticles, even though the coating has been suggested by the physico-chemical characterization, the in vivo evaluation showed the failure of this system to protect the gut wall against ulceration. On the other hand, the diclofenac-loaded nanocapsule-coated microparticles demonstrated a significant protective effect of the gastrointestinal mucosa against ulceration. The results showed the potential applicability of the NC-coated microparticles as drug delivery system.

\section{ACKNOWLEDGMENTS}

R. C. R. Beck thanks CAPES for his research grant. The authors thank the financial support of FAPERGS, CNPq and Rede de Nanobiotecnologia/CNPq/MCT-Brazil.

\section{REFERENCES}

1. Benita, S.; Microencapsulation: Methods and Industrial Applications, Marcel Dekker, New York, 1996.

2. Couvreur, P.; Dubernet, C.; Puisieux, F.; Eur. J. Pharm. Biopharm. 1995, $41,2$.

3. Schaffazick, S. R.; de Freitas, L. L.; Pohlmann, A. R.; Guterres, S. S.; Quim. Nova 2003, 26, 726.

4. Brannon-Peppas, L.; Int. J. Pharm. 1995, 116, 1.

5. Couvreur, P.; Barratt, G.; Fattal, E.; Legrand, P.; Vauthier, C.; Crit. Rev. Ther. Drug. Carrier Syst. 2002, 19, 99.

6. Bodmeier, R.; Chen, H.; J. Pharm. Pharmacol. 1988, 40, 754.

7. Conte, U.; Conti, B.; Giunchedi, P.; Maggi, L.; Drug Dev. Ind. Pharm. 1994, 20, 235.

8. Palmieri, G. F.; Wehrle, P.; Stamm A.; Drug Dev. Ind. Pharm. 1994, 20, 2859.

9. Palmieri, G. F.; Bonacucina, G.; Di Martino, P.; Martelli, S.; Drug Dev. Ind. Pharm. 2001, 27, 195.

10. Palmieri, G. F.; Bonacucina, G.; Di Martino, P.; Martelli, S.; J. Microencapsulation 2002, 19, 111.

11. Huang, Y. C.; Chiang, C. H.;Yeh, M. K; J. Microencapsulation 2003, 20, 247.

12. Wan, L. S. C.; Heng, P.; Chia, C. G. H.; Drug Dev. Ind. Pharm. 1992, 18, 997.

13. He, P.; Davis, S. S.; Illum, L.; Int. J. Pharm. 1999, 187, 53.

14. Billon, A.; Bataille B.; Cassanas, G.; Jacob, M.; Int. J. Pharm. 2000, 203, 159.

15. El-Shabouri, M. H.; Int. J. Pharm. 2002, 249, 101.

16. Lbtoutounne, H.; Chaulet, J-F.; Ploton, C.; Falson, F.; Pirot, F.; J. Controlled Release 2002, 82, 319.

17. Miyazaki, S.; Takahashi, A.; Kubo, W.; J. Pharm. Pharm. Sci. 2003, 6, 240.

18. Mu, L.; Feng, S. S.; J. Controlled Release 2003, 86, 33.

19. Ravi-Kumar, M. N. V.; Sameti, M.; Kneuer, C.; Lamprecht, A.; Lehr, C.M.; Encyclopedia of Nanoscience and Nanotechnology 2004, 9, 1.

20. Magenheim, B.; Benita, S.; S. T. P. Pharma Sci. 1995, 1, 221.

21. Pohlmann, A. R.; Soares, L. U.; Cruz, L.; Pesce da Silveira, N.; Guterres, S. S.; Curr. Drug Delivery 2004, 1, 103.

22. Guterres, S. S.; Pohlmann, A. R.; Dalla-Costa, T.; Bassani, V. L.; Müller, C. R.; Br INPI 9906081-7, 1999.

23. Guterres, S. S.; Pohlmann, A. R.; Dalla-Costa, T.; Bassani, V. L.; Müller, C. R.; French Patent 0015084, 2000.

24. Schaffazick, S. R.; Pohlmann, A. R.; Dalla-Costa, T.; Guterres, S. S.; Eur. J. Pharm. Biopharm. 2003, 56, 501.

25. Pohlmann, A. R.; Weiss, V.; Mertins, O.; Pesce da Silveira, N.; Guterres, S. S.; Eur. J. Pharm. Sci. 2002, 16, 305.

26. Müller, C. R.; Bassani, V. L.; Pohlmann, A. R.; Michalowski, C. B.; Petrovick, P. R.; Guterres, S. S.; Drug Dev. Ind. Pharm. 2000, 26, 343.

27. Müller, C. R.; Schaffazick, S. R.; Pohlmann, A. R.; De Lucca Freitas, L.; Pesce da Silveira, N.; Dalla Costa, T.; Guterres, S. S.; Pharmazie 2001, 56,864 .

28. Raffin, R. P.; Obach, E. S.; Mezzalira, G.; Pohlmann, A. R.; Guterres, S. S.; Acta Farm. Bonaerense 2001, 22, 163.

29. Guterres, S. S.; Müller, C. R.; Pohlmann, A. R.; Dalla Costa, T.; S. T. P. Pharma Sci. 2001, 11, 229.

30. Beck, R. C. R.; Pohlmann, A. R.; Guterres, S. S.; J. Microencapsulation 2004, 21, 499.

31. Fessi, H.; Puisieux, F.; Devissaguet, J.-Ph.; European Patent 0, 274, 961, 1988.

32. The United States Pharmacopoeia/The National Formulary; United States Pharmacopoeial Convention Inc.: Rockville, USA, 2004.

33. ICH-Harmonised Tripartity Guideline.Validation of Analytical Procedures: Methodology; IFPMA: Geneva, Switzerland, 1-8, 1996.

34. Brunauer, S.; Emmet, P. H.; Teller, E.; J. Am. Chem. Soc. 1938, 60, 309.

35. Barret, E. P.; Joyner, L. G.; Halenda, P. P.; J. Am. Chem. Soc. 1951, 73, 373.

36. Ammoury, N.; Dubrasquet, M.; Fessi, H.; Devissaguet, J.-Ph.; Puisieux, F.; Benita, S.; Clin. Materials 1993, 13, 121.

37. Lamprecht, A.; Yamamoto, H.; Takeuchi, H.; Kawashima, Y.; Eur. J. Pharm. Biopharm. 2004, 58, 37.

38. Kibbe, A. H.; Handbook of pharmaceutical excipients, Pharmaceutical Press: London, 2000.

39. Chiarini, A.; Tartarini, A.; Fini, A.; Arch. Pharm. 1984, 317, 268.

40. Fara, J. W.; Myrback, R. E.; Pharm. Res. 1990, 7, 616.

41. Guterres, S. S.; Fessi, H.; Barrat, G.; Puisieux, F.; Devissaguet, J.-Ph.; Pharm. Res. 1995, 12, 1. 